DOI: https://doi.org/10.36910/6775-2524-0560-2021-43-14

УДК 378.147.001.89:796:004

Миронюк Лілія Павлівна, кан. ф.-м. наук, доцент

https://orcid.org/0000-0002-4822-659X

Ройко Лариса Леонідівна, кан. пед. наук, доцент

https://orcid.org/0000-0002-7318-0925

Волинський національний університет імені Лесі Українки, м. Луцьк, Україна

\title{
ВИКОРИСТАННЯ ЗАСОБІВ ІНФОРМАЦІЙНО-КОМУНІКАЦІЙНИХ ТЕХНОЛОГІЙ У ПІДГОТОВЦІ БАКАЛАВРІВ ФАКУЛЬТЕТУ ФІЗИЧНОЇ КУЛЬТУРИ, СПОРТУ ТА ЗДОРОВ'Я
}

\begin{abstract}
Миронюк Л. П., Ройко Л. Л. Використання засобів інформаційно-комунікаційних технологій у підготовці студентів факультету фізичної культури, спорту та здоров'я. У статті проаналізовано особливості застосування інформаційно-комунікаційних технологій у дисциплінах професійного та загального циклів підготовки фахівців фізичної культури і спорту Волинського національного університету імені Лесі Українки.

Ключові слова: інформаційно-комунікаційні технології, інформаційні технології в галузі знань, фізична культура і спорт, Office 365.

Миронюк Л. П., Ройко Л.Л. Использование средств информационно-коммуникационных технологий в подготовке бакалавров факультета физической культуры, спорта и здоровья. В статье проанализированы особенности применения информационно-коммуникационных технологий в дисциплинах профессионального и общего циклов подготовки специалистов физической культуры и спорта Волынского национального университета имени Леси Украинки.

Ключевые слова: информационно-коммуникационные технологии, информационные технологии в области знаний, физическая культура и спорт, Office 365.
\end{abstract}

Myroniuk L. P., Royko L. L. Use of information and communication technologies in the preparation of students of the Faculty of Physical Culture, Sports and Health. The article analyzes the peculiarities of the use of information and communication technologies in the disciplines of the professional and general cycles of training of specialists in physical culture and sports of Lesya Ukrainka Volyn National University.

Keywords: information and communication technologies, information technologies in the field of knowledge, physical culture and sports, Office 365 .

Постановка наукової проблеми. Соціально-економічний прогрес розвинених країн характеризується інформатизацією всіх сфер людської діяльності, у тому числі і професійної. В освіті, як складовій частині, інформатизація передбачає систему методів, процесів та програмно-технічних засобів, інтегрованих з метою збору, обробки, зберігання, розповсюдження і використання іiі на користь споживачів [7]. Наявність в освітніх програмах курсів, пов'язаних 3 інформаційними технологіями, надає студентам можливості отримання інформації щодо комп'ютерної грамотності не тільки у своїй професійній діяльності, але і у всіх сферах життя суспільства, що допомагає поглибленню професійних знань, наукового та культурного світогляду.

В умовах сьогодення стає очевидним, що будь який напрямок спортивної індустрії неможливий без застосування засобів сучасних інформаційно-комунікаційних технологій. Перед вищими навчальними закладами постає завдання підготовки фахівців, здатних орієнтуватися у просторі наукової інформації та сучасних інформаційних технологіях. 3 цією метою на факультеті фізичної культури, спорту та здоров'я Волинського національного університету імені Лесі Українки у цикл загальної підготовки навчального плану бакалавра другого року навчання включено навчальну дисципліну «Інформаційні технології в галузі знань».

Аналіз досліджень. Дослідженню питань інформатизації освіти нині приділяється значна увага. Зокрема, І. Булах, М. Жалдак, Г. Козлакова, А. Коломієць, О. Лядська [8] вивчали використання інформаційно-комунікаційних технологій у професійній діяльності; В. Безпалько, О. Довгялло, М. Кадемія, О. Качан [6], І. Мархель, І. Підласий - психолого-педагогічні основи застосування комп’ютерних технологій у закладах вищої освіти; Р. Гуревич, П. Дмитренко, Н. Корсунська, В. Олійник, О. Собаєва, П. Таланчук - організацію і впровадження дистанційної освіти тощо.

Питанням впровадження інформаційних технологій у навчальний процес вищих навчальних закладів фізкультурного профілю присвятили свої праці: В. Ашанін, В. Бізін, В. Бубнов [2], Є. Блещунова, В. Гамалій, Т. Дорофєєва [1], Т. Івчатова [4], С. Срмаков, Р. Клопов [7], І. Заневський, М. Маліков, В. Шаповалова.

Поділяємо думку О. Ільків [5], О. Пришляка, В. Матвіїва, що жодна інша навчальна дисципліна не використовує міжпредметні зв'язки так широко, як «Інформаційні технології в галузі знань». Саме у процесі викладання цього курсу формується інформаційна культура та грамотність майбутніх фахівців. 
Метою статті $є$ аналіз особливостей застосування інформаційно-комунікаційних технологій у дисциплінах професійного циклу підготовки фахівців фізичної культури і спорту.

Виклад основного матеріалу й обгрунтування отриманих результатів дослідження. Авторами статті було проаналізовано навчальний план бакалавра спеціальності «017 Фізична культура і спорт» (галузь знань 01 «Освіта»; освітня програма (спеціалізація) «Фізична культура і спорт"; кваліфікація - тренер з виду спорту, інструктор-методист спортивно-масової роботи / тренер з виду спорту, інструктор-методист фітнесу і туризму / тренер з виду спорту, інструктор-методист; форма навчання - денна; термін навчання - 3 роки 10 міс., на базі повної загальної середньої освіти), згідно якого студенти вивчають наступні навчальні дисципліни:

$>$ ичкл професійної підготовки: «Гімнастика та методика іiі викладання», «Рухливі ігри та методика їх викладання», «Спортивно-педагогічне вдосконалення з видів спорту», «Плавання та методика його викладання», «Туризм», «Біомеханіка»; «Теорія спорту», «Фітнес», «Спортивні ігри та методика їх викладання», «Легка атлетика та методика ії̈ викладання», «Основи масажу»;

иикл загальної підготовки: «Україна у європейському історичному та культурному контекстах», «Іноземна мова (за професійним спрямуванням)», «Творчий феномен Лесі Українки», «Анатомія людини», «Психологія фізичної активності», «Фізіологія людини», «Історія фізичної культури та олімпійський спорт», «Основи громадянського суспільства та політичних знань», «Основи медичних знань та БЖД», «Українська мова (за професійним спрямуванням)», «Філософія», «Інформаційні технології в галузі знань», «Основи менеджменту, маркетингу та адміністрування у сфері ФВ та спорту», «Теорія і методика фізичного виховання», «Сучасні методи дослідження в олімпійському та професійному спорті», «Спортивна педагогіка».

Як показує досвід, використання інформаційно-комунікаційних технологій у дисциплінах професійного циклу бакалаврів фізичної культури і спорту можна здійснити:

-акцентуючи увагу студентів на тому, що інформаційні технології у фізичній культурі застосовуються у широкому спектрі напрямів (навчальному процесі; спортивних тренуваннях; як засіб автоматизації процесів обробки результатів змагань та наукових досліджень; при організації моніторингу фізичного стану та здоров'я тих, хто займається; у спортивному менеджменті; рекламній, видавничій і підприємницькій діяльності у сфері фізичної культури й спорту);

-демонструючи студентам конкретні приклади задач, розв’язання яких значно спрощується 3 використанням відповідних програмних засобів;

-пропонуючи студентам у якості індивідуальних домашніх завдань підготовку презентацій про сучасні мобільні додатки, новітні гаджети, які можуть бути використані на заняттях спортом;

- розповідаючи студентам про різні дистанційні курси навчання.

Волинський національний університет імені Лесі Українки має власний університетський портал - Office 365 (рис. 1.), де у кожного студента та викладача $є$ свій обліковий запис, доступ до якого можна здійснити навіть зі своїх мобільних пристроїв. Це значно полегшує навчання студентів саме спеціальності «Фізична культура і спорт», які досить часто не мають можливості бути присутніми на парах через участь у різноматнітних змаганнях та тренуваннях.

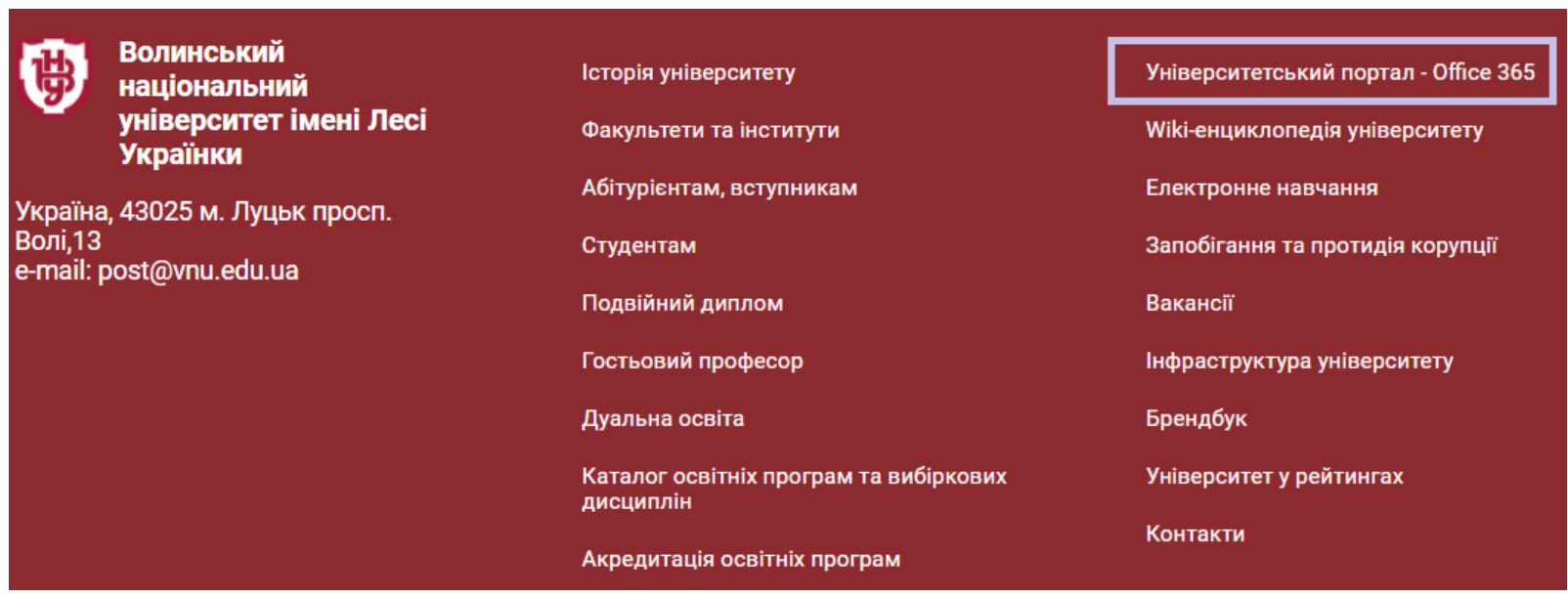

Рис. 1. Фрагмент зображення сторінки входу в університетський портал Office365

Microsoft Office 365 for Education має надійний комплекс інструментів для здійснення освітньої діяльності студентів та викладачів як в умовах стаціонарного навчання, так і дистанційного.

Пошта Outlook дає можливіть надсилати листи, навіть якщо електронна адреса отримувача невідома, достатньо лише вказати його ім'я та обрати із запропонованого списку студентів чи 
викладачів університету. Викладач має можливість створювати відповідні групи, що економить час при надсиланні завдань чи вказівок (рис. 2).

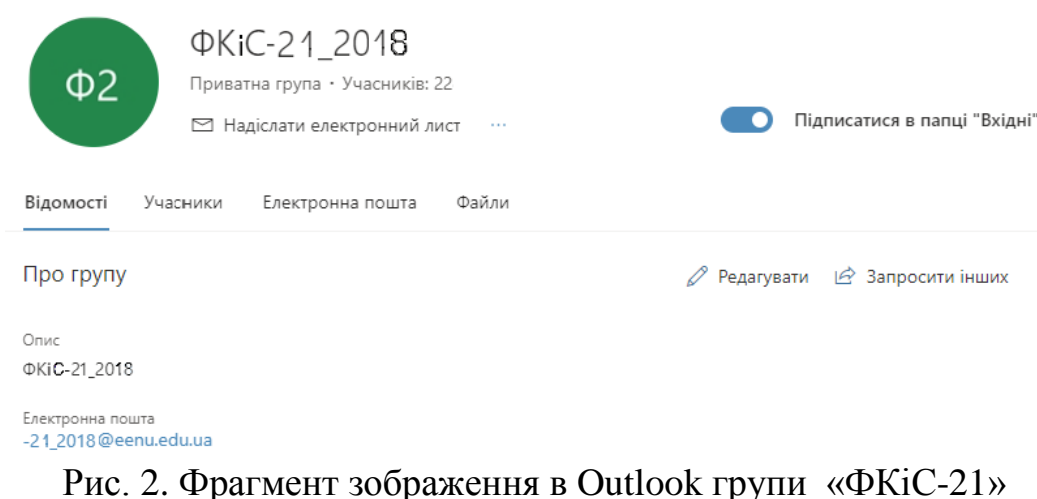

Тестові завдання для підсумкового контролю знань, який проводиться у вигляді контрольної роботи, створені за допомогою надбудови Microsoft Forms. У день її написання кожен студент отримує відповідне посилання в Outlook на Forms [9].

Очевидно, що Word стане для студентів у нагоді при підготовці рефератів, курсових робіт.

3 метою підвищення рівня зацікавленості навчальною дисципліною «Інформаційні технології в галузі знань» студентам пропонується як індивідуально-дослідне завдання створення презентації PowerPoint на тему «Спеціальні мобільні додатки в спорті». Студенти успішно справляються 3 завданням та опрацьовують інформацію про різноманітні додатки - RunKeeper; Nike; miCoach; Sworkit Lite; Fleetly; Крокомір; FatSecret тощо. Деякі студенти виявляють бажання підготувати презентації про фітнес-браслети, інші - про дистанційні тренування.

Уміння виконувати обчислення за допомогою табличного процесора Excel допоможе розв'язувати задачі, пов'язані з певними розрахунками. Зокрема, завдання з навчальної дисципліни «Біомеханіка» можуть бути досить швидко виконані, якщо студенти скористаються Ехсеl. Нижче наведено приклади застосувань математичних та статистичних функцій в Excel Office 365.

1. За даними показника «Довжина гомілки» 40; 41,5; 45; 40; 44; 46; 39; 43; $54 ; 43$ знайти числові характеристики вибірки:

а) вибіркове середнє $\bar{x}$ (середнє арифметичне);

b) вибіркову дисперсію $s^{2}=\frac{\sum\left(x_{i}-\bar{x}\right)^{2}}{n}$;

c) вибіркове середнє квадратичне відхилення $s=\sqrt{s^{2}}$;

d) коефіцієнт варіації $V=\frac{s}{\bar{x}} \cdot 100$;

е) похибку репрезентативності $m=\frac{s}{\sqrt{n}}$.

Замість громіздких формул та обчислень варто скористатись відповідними функціями Excel (рис. 3.):

-для обчислення вибіркового середнього: AVERAGE (в інших версіях Excel, наприклад, Excel 2003: СРЗНАЧ); дИСП);

-для обчислення вибіркової дисперсії: VARPA (в інших версіяx Excel, наприклад, Excel 2003:

- для обчислення вибіркового середнього квадратичного відхилення: SQRT (в інших версіях Excel, наприклад, Excel 2003: КОРЕНь). 


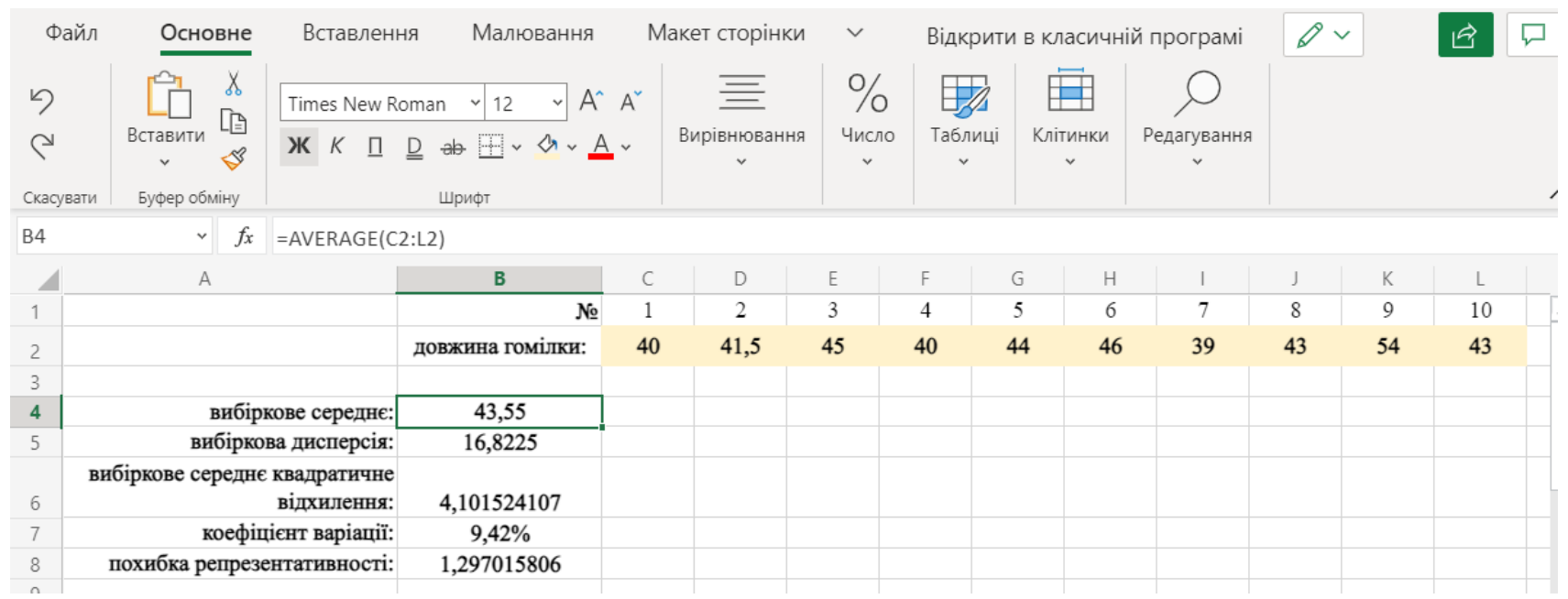

Рис. 3. Розв’язання завдання з «Біомеханіки» в Excel Office 365

Аналогічні обчислення студенти можуть виконати для показників «Довжина стопи» та «Довжина нижньої кінцівки» за даними: $23 ; 25 ; 26 ; 27 ; 27 ; 24 ; 26 ; 26 ; 26 ; 26,5$ - для стопи;

98,$5 ; 105 ; 108 ; 109 ; 110 ; 100 ; 105 ; 100 ; 124 ; 116$ - для нижньої кінцівки.

2. Визначити, чи значний зв'язок між довжиною стегна та обсягом шиї за такими даними відповідних показників:

$39 ; 44 ; 44 ; 45 ; 43 ; 42 ; 40 ; 50 ; 39 ; 48$ - для стегна

52,$5 ; 52 ; 54 ; 61 ; 60 ; 49 ; 50 ; 55 ; 63 ; 63$ - для шиї,

обчислити коефіцієнт кореляції

$$
r=\frac{\frac{\sum\left(x_{i}-\bar{x}\right) \cdot\left(y_{i}-\bar{y}\right)}{n}}{\sigma_{x} \cdot \sigma_{y}},
$$

та зробити висновок про ступінь зв'язку, враховуючи наступну теоретичну інформацію:

$r=0$ - відсутній зв'язок;

$r=0 \div|0,3|-$ дуже слабкий зв'язок;

$r=|0,3| \div|0,5|-$ слабкий зв'язок;

$r=|0,5| \div|0,7|-$ значний зв'язок;

$r=|0,7| \div|0,99|-$ сильний зв'язок.

Замість громіздких формул та обчислень варто скористатись функцією CORREL (в інших версіях Excel, наприклад, Excel 2003: КОРРЕЛ) (рис. 4.).

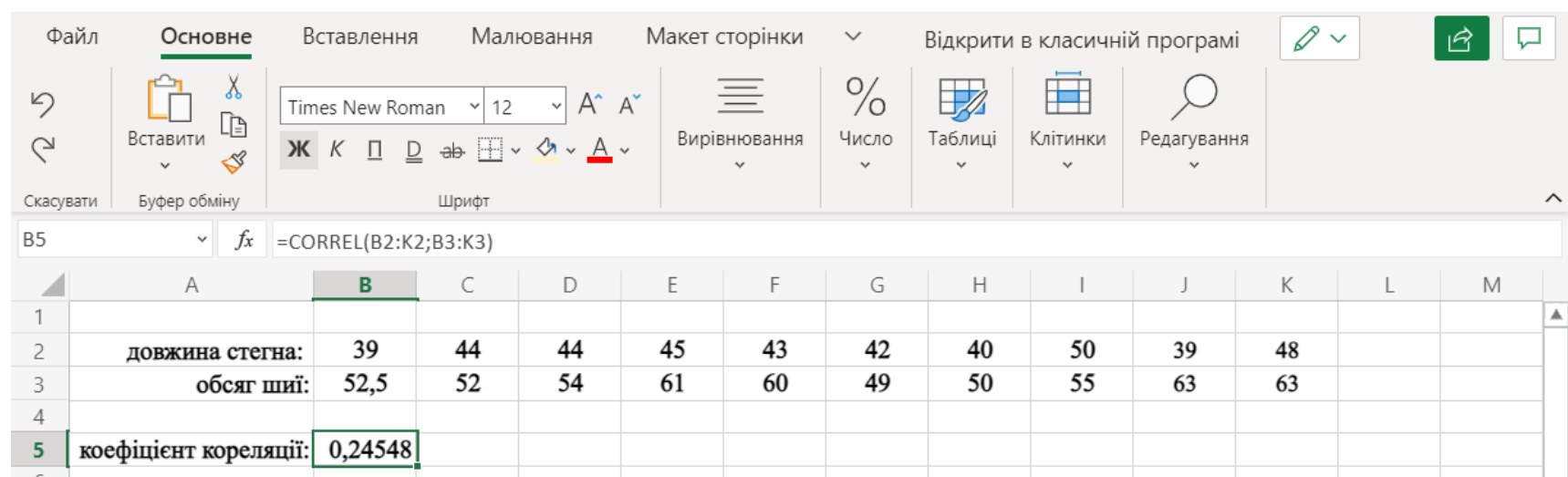

Рис. 4. Розв’язання завдання з «Біомеханіки» в Excel Office 365

Оскільки $r \approx 0,25$, то зв'язок дуже слабкий.

Аналогічні обчислення студенти можуть виконати для визначення зв'язку між обсягом передпліччя та обсягом талії за такими даними відповідних показників:

$$
\begin{aligned}
& \text { 21; 20; 28; 28; 32; 24; 30; 35; 27; } 30 \text { - для передпліччя; } \\
& \text { 71; 69; 75; 76; 80; 70; 78; 77; 70; } 91 \text { - для талії. }
\end{aligned}
$$

Знання баз даних Access допоможе збирати й упорядковувати різного роду інформацію (наприклад, про учасників змагань). 
При опрацюванні теми «Розробка матеріалів засобами Microsoft Publisher» студенти факультету фізичної культури, спорту та здоров'я, використовуючи шаблони програми, створюють буклети (з інформацією про спортивні змагання, матчі, турніри, чемпіонати, бої, досягнення відомих спортсменів); промо-буклети для тематичних заходів, візуалізацію навчально-наукового матеріалу; листівки; календарі; грамоти тощо.

Студенти також ознайомлені і працюють з хмарними додатками Google: Classroom, Drive, Docs, Calendar, Gmail тощо.

Корисним для бакалаврів факультету фізичної культури, спорту та здоров'я є хмарний сервіс WolframAlpha, доступ до якого здійснюється через посилання http://www.wolframalpha.com у браузері (без реєстрації користувача), а англомовний інтерфейс базується на використанні рядка для введення запитів.

Даний сервіс можна застосовувати для побудови різного роду графіків, зображень, поверхонь.

За допомогою вкладинки «Personal health» сервісу WolframAlpha студенти можуть ознайомлюватися $з$ даними про харчування та потужними калькулятори для схуднення, обчислювати та порівнювати поживні речовини у звичайних продуктах харчування та фірмових продуктах; підраховувати калорії, спалені сотнями різних видів діяльності, з урахуванням віку, ваги та статі.

Наприклад, якщо ввести в рядок для запитів «swimming» і задати наступні параметри:

- час: $30 \mathrm{xв;}$

- швидкість: 2 км/год;

- стать: ч;

- вага: 80 кг,

то отримаємо інформацію про метаболічні властивості та частоту пульсу плавця (рис. 5).

\begin{tabular}{|c|c|}
\hline energy expenditure & 1406 kJ (kilojoules) \\
\hline fat burned & 0.044 kg (kilograms) \\
\hline oxygen consumption & $67.2 \mathrm{~L}$ (liters) \\
\hline metabolic equivalent & 8 metabolic equivalents \\
\hline \multicolumn{2}{|c|}{ (estimates based on CDC standards) } \\
\hline \multicolumn{2}{|l|}{ Heart rate: } \\
\hline estimated heart rate & (142.7 to 192.5$) \mathrm{bpm}$ (beats per minute) \\
\hline heart rate reserve & $124 \mathrm{bpm}$ (beats per minute) \\
\hline
\end{tabular}

Рис. 5. Фрагмент зображення даних, отриманих базою знань WolframAlpha

Крім знаходження зазначених характеристик, WolframAlpha знаходить й інші, а також ілюструє порівняльну характеристику для чоловіків та жінок, з урахуванням їх віку (рис. 6).
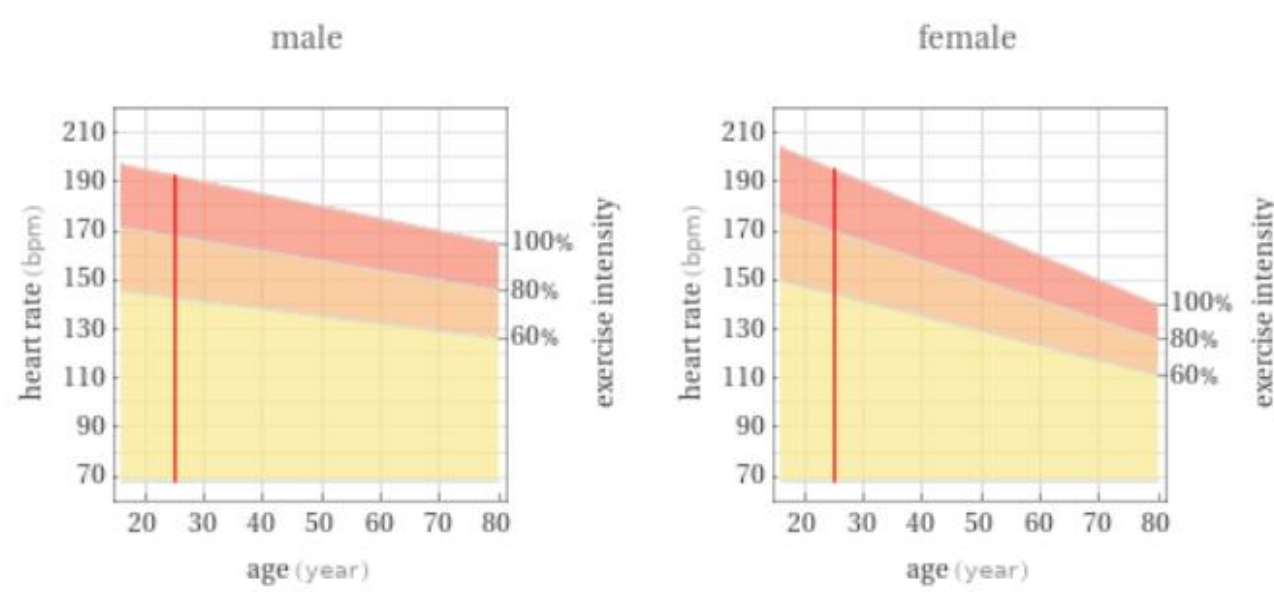

Рис. 6. Фрагмент зображення порівняльної характеристики, отриманих базою знань WolframAlpha

Варто наголосити студентам, що при вивченні навчальної дисципліни «Іноземна мова (за професійним спрямуванням)» та підготовці до здачі заліків чи екзаменів вони можуть скористатися 
програмними засобами вивчення іноземної мови («Triple Play Plus»; «English Platinum 2000»; «Інтенсивний курс англійської мови», «Кращий курс англійської мови» тощо); комп’ютеризованими курсами («Reward», «ElanTes», «Edusof» та ін.); мовними центрами дистанційного та онлайн навчання, скайп уроками (Студія іноземних мов «FREE WAY online school»; Школа іноземних мов UNIVERSE CENTER; Центр вивчення іноземних мов по Skype «SkyLingua»; Лінгвістичний центр «Світ Іноземних Мов»; Онлайн-школа англійської мови «Englishgrad» тощо).

При вивченні навчальної дисципліни «Фітнес» студентам варто навести приклади комп’ютерних програм, які використовуються у сфері оздоровчого фітнесу. Серед них можна відмітити [3] такі, що

- слугують для організації самостійних занять: «Yourself Fitness» (Respondesign in.), «Open Fitness», «Фітнес для жінок» (розробник - Д. Луценко);

- $\epsilon$ електронними щоденниками тренувального процесу: «Exlib» (Norsk Video Digitech AS);

- $\epsilon$ програмами, що забезпечують діагностику, профілактику та зміцнення здоров'я на основі коригування способу життя і проведення заходів по оздоровленню: «Здоров'я сім’ї» (розробник I. Дроздюк);

- $\epsilon$ програмами вдосконалення організації занять із використанням засобів фітбол-тренінгу: «Fitball training» (розробник - О. Лядська) [8].

При вивченні теми «Створення Веб-сайту» майбутні фахівці фізичної культури і спорту ознайомлюються з основними прийомами, які необхідні для створення Веб-сайтів та Веб-сторінок, засвоюють методологію та технологію оформлення інтерфейсу Веб-сторінок. Створення студентами власної Веб-сторінки засобами HTML (HyperText Markup Language) дозволяє закріпити поняття про мову розмітки гіпертексту HTML та способи виконання дій з командами-тегами для створення Вебсторінок, з якими документ визначений та структурований.

Процес підвищення інтересу до спорту і включення молоді у фізкультурно-спортивну діяльність, на сьогодні, можна забезпечити створенням on-line уроків за участю переможців різного роду змагань. Як засвідчують дослідження, інтерес до спортивних сайтів постійно зростає. На перші позиції виходять інтернет-технології, котрі дозволяють створення ефективних систем програмно-методичного, ресурсного забезпечення фізкультурної освіти населення.

Висновки та перспективи подальшого дослідження. Використання інформаційнокомунікаційних технологій у професійній підготовці майбутніх фахівців фізичної культури і спорту $є$ рушієм інноваційних процесів у вищій фізкультурній освіті. Знання, вміння та навички отримані при вивченні дисципліни «Інформаційні технології в галузі знань», мають стати початком для застосування сучасних інформаційних технологій при вивченні загальних, професійно-орієнтованих і спеціальних дисциплін у процесі авдиторної та самостійної роботи студентів. Даний навчальний курс, завдяки ретельно дібраному викладачем матеріалу, розширює кругозір студентів, допомагає краще розуміти інші навчальні дисципліни.

Серед перспектив досліджень у цьому напрямку варто виділити створення методичних матеріалів, посібників, курсів лекцій, збірників задач, що враховували б професійну спрямованість студентів з використанням інформаційно-комунікаційних технологій.

\section{Список бібліографічного опису}

1. Ажиппо О. Ю., Дорофєєва Т. І. Використовування комп’ютерних технологій в системі педагогічного контролю у спорті. Теорія та методика фізичного виховання. 2007. № 11. С. 3-6.

2. Бубнов В. Формування інформаційної культури майбутніх фахівців фізичного виховання, спорту та рекреації. Молода спортивна наука України : зб. наук. пр. в галузі фіз. культури та спорту. Л., 2004. Вип. 8. т. 4. С. 43-46.

3. Гончарова Н, Денисова Л., Усиченко В. Використання сучасних інформаційних технологій у сфері оздоровчого фітнесу. Фізична культура, фізичне виховання різних груп населення: збірник наукових праць. 2012. №2(18). С. $163-166$.

4. Івчатова Т. В. Інформаційні технології у фізичному вихованні студентської молоді. Педагогіка, психологія та медико-біологічні проблеми фізичного виховання і спорту. Науковий журнал. Харків, 2010. №9. С. 30-33.

5. Ільків О., Пришляк О., Матвіїв В. Міжпредметні зв'язки як один із факторів формування інформаційної культури майбутніх фахівців фізичної культури та спорту. Молода спортивна наука України: зб. наук. пр. $з$ галузі фіз. виховання, спорту і здоров'я людини / за заг. ред. Євгена Приступи. Львів, 2013. Вип. 17, т. 4. С. 71-77.

6. Качан О. А. Упровадження інноваційних технологій у фізкультурно-оздоровчу та спортивну діяльність закладів освіти: навчально-методичний посібник. Слов'янськ: Витоки, 2017. 138 с.

7. Клопов Р. В. Сучасний стан готовності майбутніх фахівців 3 фізичного виховання та спорту до застосування інформаційних технологій у професійній діяльності. Педагогіка формування творчої особистості у вищій і загальноосвітній школах. 2013. Вип. 33. С. 567-573.

8. Лядська О. Ю. Застосування комп’ютерної програми «Fitball training» для удосконалення організації фізкультурно-оздоровчих занять 3 жінками першого зрілого віку із застосуванням футболу. Фізична культура, фізичне виховання різних груп населення. Педагогіка, психологія та медико-біологічні проблеми фізичного виховання і спорту. 2010. 12. C. $76-80$. 
9. Мамчич Т. І., Миронюк Л. П., Ройко Л. Л. Досвід використання інформаційно-комунікаційних технологій при викладанні математичних дисциплін в умовах дистанційного навчання. Науковий журнал «Комп'ютерно-інтегровані технології: освіта, наука, виробництво». ЛНТУ, 2020. №39, С. 70-77.

\section{References}

1. Azhyppo O. Yu., Dorofieieva T. I. Vykorystovuvannia kompiuternykh tekhnolohii v systemi pedahohichnoho kontroliu u sporti. Teoriia ta metodyka fizychnoho vykhovannia. 2007. № 11. S. 3-6.

2. Bubnov V. Formuvannia informatsiinoi kultury maibutnikh fakhivtsiv fizychnoho vykhovannia, sportu ta rekreatsii. Moloda sportyvna nauka Ukrainy : zb. nauk. pr. v haluzi fiz. kultury ta sportu. L., 2004. Vyp. 8. t. 4. S. 43-46.

3. Honcharova N., Denysova L., Usychenko V. Vykorystannia suchasnykh informatsiinykh tekhnolohii u sferi ozdorovchoho fitnesu. Fizychna kultura, fizychne vykhovannia riznykh hrup naselennia: zbirnyk naukovykh prats. 2012. №2(18). S. 163-166.

4. Ivchatova T. V. Informatsiini tekhnolohii u fizychnomu vykhovanni studentskoi molodi. Pedahohika, psykholohiia ta medyko-biolohichni problemy fizychnoho vykhovannia i sportu. Naukovyi zhurnal. Kharkiv, 2010. №9. S. 30-33.

5. Ilkiv O., Pryshliak O., Matviiv V. Mizhpredmetni zviazky yak odyn iz faktoriv formuvannia informatsiinoi kultury maibutnikh fakhivtsiv fizychnoi kultury ta sportu. Moloda sportyvna nauka Ukrainy: zb. nauk. pr. z haluzi fiz. vykhovannia, sportu i zdorovia liudyny / za zah. red. Yevhena Prystupy. Lviv, 2013. Vyp. 17, t. 4. S. 71-77.

6. Kachan O. A. Uprovadzhennia innovatsiinykh tekhnolohii u fizkulturno-ozdorovchu ta sportyvnu diialnist zakladiv osvity: navchalno-metodychnyi posibnyk. Sloviansk: Vytoky, 2017. $138 \mathrm{~s}$.

7. Klopov R. V. Suchasnyi stan hotovnosti maibutnikh fakhivtsiv z fizychnoho vykhovannia ta sportu do zastosuvannia informatsiinykh tekhnolohii u profesiinii diialnosti. Pedahohika formuvannia tvorchoi osobystosti u vyshchii i zahalnoosvitnii shkolakh. 2013. Vyp. 33. S. 567-573.

8. Liadska O. Yu. Zastosuvannia kompiuternoi prohramy «Fitball training» dlia udoskonalennia orhanizatsii fizkulturnoozdorovchykh zaniat z zhinkamy pershoho zriloho viku iz zastosuvanniam futbolu. Fizychna kultura, fizychne vykhovannia riznykh hrup naselennia. Pedahohika, psykholohiia ta medyko-biolohichni problemy fizychnoho vykhovannia i sportu. 2010. 12. S. 76-80.

9. Mamchych T. I., Myroniuk L. P., Roiko L. L. Dosvid vykorystannia informatsiino-komunikatsiinykh tekhnolohii pry vykladanni matematychnykh dystsyplin v umovakh dystantsiinoho navchannia. Naukovyi zhurnal «Kompiuterno-intehrovani tekhnolohii: osvita, nauka, vyrobnytstvo». LNTU, 2020. №39, S. 70-77. 